\title{
Parental DNA sequence is critical family history in clinical genomics
}

\author{
Michael F. Murray, MD¹
}

The way that we think about family history acquisition must evolve. Approximately $50 \%$ of cases in which clinical wholeexome sequencing (WES) achieves a molecular diagnosis rely on evidence that the pathogenic or likely pathogenic variant found in that proband constitutes a de novo event (Table 1). ${ }^{1-4}$ The recognition of a de novo event is contingent on the availability of biparental DNA sequence data to draw that conclusion. The exception to biparental samples is the ascertainment of a de novo event in the mitochondrial DNA, which can be determined with supporting maternal DNA evidence alone. Despite a clear opportunity to increase the diagnostic yield of this expensive clinical test by submitting trio samples, ${ }^{3,4}$ only about half of the proband samples received by Posey et al. ${ }^{5}$ were accompanied by biparental samples. These observations prompt the question "What is the ideal family history data set for patient care in the era of genomic medicine?"

For a long time, many considered the gold-standard family history data set to be a three-generation pedigree that was annotated with health history information. It seemed reasonable and achievable to hold this up as the ideal comprehensive family history data set to be sought in clinical care. ${ }^{6}$ This goal began to emerge prior to knowledge of specific gene-disease associations and is based on an appreciation of the fact that this family history data set can be used to impute certain types of inherited DNA variations-for example, obligate carriers of pathogenic variants on the $\mathrm{X}$ chromosome in Duchenne muscular dystrophy. ${ }^{6,7}$ However, imputation is imprecise, and it is now becoming clear from early clinical applications of genomic sequencing that optimal family history data in this century need to include DNA variant data from relatives (most especially parents) in addition to their health history information.

In this issue of Genetics in Medicine, Posey and colleagues ${ }^{5}$ report the molecular diagnostic experience of WES in adult patients, with data from a leading clinical reference laboratory. The authors found that the number of WES-based molecular diagnoses decreased as patient age increased. It should give us pause to learn that at a leading clinical laboratory the molecular diagnosis rate for WES decreased from $25 \%$ in the general cohort to $10 \%$ among samples from the probands over 30 years of age. ${ }^{2,5}$ What underlies the reduction in diagnostic yield to
$10 \%$ ? Certainly consideration should be given to whether and how biologic factors or case selection biases could contribute to the inverse correlation between age and diagnosis. That analysis notwithstanding, a clear contributor to the diminished molecular diagnoses in the older patient group is the paucity of diagnoses supported by trio analysis (Table 1 ). ${ }^{5}$

Laboratories are appropriately cautious when attributing disease to novel missense variants; however, this attribution can be made with much greater confidence in the setting of three findings: the novel missense variant is in a plausible gene, it is shown through trio analysis to be de novo, and the parental medical history is negative for the phenotype in question. In the cohort reported by Posey et al., ${ }^{5}$ all 13 novel autosomal-dominant missense variants were in patients under the age of 30 , and 11 of those 13 had parental samples to inform the interpretation as de novo. Posey et al. found that, overall, $61.4 \%$ of autosomal-dominant diagnoses were attributable to de novo variants. These authors noted that when parental samples were available, de novo events were detected in $81.8 \%$ of dominant diagnoses. The finding in this series that the majority of autosomaldominant diagnoses were de novo is consistent with findings from other major case series. The observation of diminished diagnosis in probands over 30 years old occurs in the context of the absence of a reasonably expected number of molecular diagnoses in which autosomal-dominant disease is attributed to novel missense variants.

Parental DNA sequence data are critical family history data for molecular diagnoses using genomic technologies. While de novo variation detection has appeared as an early example of the critical importance of familial DNA sequence data in genomic diagnosis, we cannot expect that this will be the only use for familial DNA sequence data. As clinical genomic diagnostic applications grow, it will become common for the interpretation of novel variants in both monogenic and polygenic diseases to depend on the evaluation of close relatives with those same variants. In instances where private mutations of potential import are revealed, but for which there is not an available ex vivo functional assay, family history data will be used as an in vivo "functional assay" to inform the variant interpretation. It is also reasonable to expect that, at some point, familial analysis

${ }^{1}$ Geisinger Health System, Forty Fort, Pennsylvania, USA. Correspondence: Michael F. Murray (mfmurray1@geisinger.edu)

Submitted 14 October 2015; accepted 27 October 2015; advance online publication 14 January 2016. doi:10.1038/gim.2015.177 
Table 1 Published cohorts from three different clinical testing laboratories

\begin{tabular}{|c|c|c|c|c|c|c|}
\hline Cohort & Laboratory & Probands, $n$ & $\begin{array}{c}\text { Probands with } \\
\text { molecular } \\
\text { diagnosis, } n(\%)\end{array}$ & $\begin{array}{l}\text { Probands with a } \\
\text { de novo molecular } \\
\text { diagnosis, } n(\%)\end{array}$ & $\begin{array}{l}\text { Cases molecularly } \\
\text { diagnosed based on a } \\
\text { de novo finding, \% }\end{array}$ & Reference \\
\hline 1 & Baylor & 250 & $62(24.8)$ & $29(11.6)$ & 46.7 & 1 \\
\hline 3 & UCLA & 814 & $213(26)$ & $127(15.6)$ & 59.6 & 3 \\
\hline 4 & Ambry & 500 & $152(30)$ & $80(16)$ & 52.6 & 4 \\
\hline Cohorts 1-4 & & 3,564 & $931(26.1)$ & $484(13.6)$ & 52.0 & \\
\hline $5 a$ & Baylor & $\begin{array}{c}255 \\
\text { (adult cohort, subgroup } \\
<30 \text { years old) }\end{array}$ & $61(23.9)$ & $28(11.0)$ & 45.9 & 5 \\
\hline $5 b$ & Baylor & $\begin{array}{c}231 \\
\text { (adult cohort, subgroup } \\
\geq 30 \text { years old) }\end{array}$ & $24(10.4)$ & $2(0.9)$ & 8.3 & 5 \\
\hline
\end{tabular}

Summary data from five publications include data from three clinical laboratories. Overall, data from 3,778 probands (863 adult probands and 2,915 pediatric probands) are included. Cohort 1 includes 28 (11.2\%) adults, cohort 2 includes $244(12.2 \%)$ adults, cohort 3 includes $294(36.1 \%)$ adults, cohort 4 includes 83 (16.5\%) adults, cohorts 1-4 include 649 (18.2\%) adults, and cohort 5 includes 214 unique adult probands and 272 probands from cohorts 1 and 2.

of the segregation of an epigenetically marked DNA sequence will routinely contribute to the clinical interpretation of the proband's sequence data.

Genomically informed practitioners who are ordering WES likely understand that there is value in obtaining parental DNA. Why, then, is that source of family history data so frequently missing from the analysis? The twofold answer is that the parental DNA is not easy to obtain, and its inclusion as a factor in the diagnostic success of all cases needs to be more heavily emphasized. Obstacles to obtaining parental samples include estrangement, death, mistaken paternity, lack of health insurance support, and lack of practical infrastructure. Of these obstacles, parental death, estrangement, and lack of health insurance support are likely far more common among cases of adult probands. Even if parents of adult patients are alive, connected, and motivated to help, when they are over 65 years old and on Medicare, the exercise of bringing them into clinic to draw peripheral blood samples for the benefit of their adult child always requires improvisation.

The infrastructure for collecting, storing, and sequencing parental DNA is lacking. When Guttmacher, Collins, and Carmona $^{8}$ announced in 2004 the creation of the Surgeon General's Family Health Portrait as an electronic family history tool for collecting and storing family health history information, it helped to set off a wave of interest around the infrastructure needs related to the acquisition and storage of a standard three-generation pedigree and associated health information. ${ }^{9}$ The infrastructure needs around collecting and storing parental DNA are different but solvable. The combined efforts of the genomics community, the government, the payer community, and private industry could create a robust system for collecting and storing DNA that could then be sequenced later when the need arises. Approximately 2.5 million Americans die each year, and with them is lost a tremendous amount of valuable history. ${ }^{10} \mathrm{~A}$ significant improvement in the population's parental DNA data set would occur if a discussion about the how and why of saving DNA and health history information was included in advanced directive discussions, retirement paperwork, Medicare enrollment, and other routine discussions that touch on health-care planning.

Let's examine the costs and benefits of resetting the expectations for clinical family history. Pilot studies should be pursued to compare traditional family history data sets with data sets that include both the story and the sequence. For now, laboratories and genomics providers need to educate patients and colleagues about the critical importance of linking health history and sequence data from parents to the proband as a minimal data set when clinical genomic testing is undertaken. I think that, ultimately, family history in the 21 st century will move beyond imputation and will be defined as the core information set that allows a person's DNA-based diagnoses and risk assessments to be placed in the context of observed genotypephenotype correlations in relatives.

\section{DISCLOSURE}

The author declares no conflict of interest. He is paid through Geisinger Health System and funded by NIH and PA Cure and through a collaboration between Geisinger and Regeneron Pharmaceuticals.

\section{REFERENCES}

1. Yang Y, Muzny DM, Reid JG, et al. Clinical whole-exome sequencing for the diagnosis of mendelian disorders. N Eng/ J Med 2013;369:1502-1511.

2. Yang $Y$, Muzny DM, Xia F, et al. Molecular findings among patients referred for clinical whole-exome sequencing. JAMA 2014;312:1870-1879.

3. Lee $H$, Deignan JL, Dorrani N, et al. Clinical exome sequencing for genetic identification of rare Mendelian disorders. JAMA 2014;312:1880-1887.

4. Farwell KD, Shahmirzadi L, El-Khechen D, et al. Enhanced utility of familycentered diagnostic exome sequencing with inheritance model-based analysis: results from 500 unselected families with undiagnosed genetic conditions. Genet Med 2015;17:578-586.

5. Posey JE, Rosenfeld JA, James RA, et al. Molecular diagnostic experience of whole-exome sequencing in adult patients. Genet Med E-pub ahead of print 3 December, 2015. 
6. Wattendorf DJ, Hadley DW. Family history: the three-generation pedigree. Am Fam Physician 2005;72:441-448.

7. Sibert JR, Harper PS, Thompson RJ, Newcombe RG. Carrier detection in Duchenne muscular dystrophy. Evidence from a study of obligatory carriers and mothers of isolated cases. Arch Dis Child 1979;54:534-537.

8. Guttmacher AE, Collins FS, Carmona RH. The family history-more important than ever. NEngl J Med 2004;351:2333-2336.
9. Feero WG, Facio FM, Glogowski EA, et al. Preliminary validation of a consumeroriented colorectal cancer risk assessment tool compatible with the US Surgeon General's My Family Health Portrait. Genet Med 2015;17:753-756.

10. Centers for Disease Control and Prevention, National Center for Health Statistics. Underlying Cause of Death 1999-2013 on CDC WONDER Online Database, released 2015. http://wonder.cdc.gov/ucd-icd10.html. Accessed 7 September 2015. 